Disponível em

http://www.anpad.org.br/rac

RAC, Rio de Janeiro, v. 19, Edição Especial, art. 2, pp. 20-37, Maio 2015

http://dx.doi.org/10.1590/1982-7849rac20151789

(c) EY-No

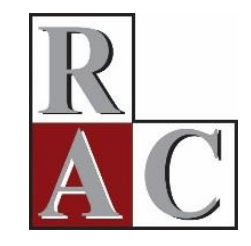

\title{
Rebalanceamento da Estrutura de Capital: Endividamento Setorial e Folga Financeira
}

Capital Structure Rebalancing: Industry Leverage and Financial Slack

Anderson Luis Saber Campos Universidade Metodista de São Paulo

Wilson Toshiro Nakamura Universidade Presbiteriana Mackenzie

Artigo recebido em 18.12.2013. Última versão recebida em 24.09.2014. Aprovado em 28.09.2014. 


\title{
Resumo
}

Admitindo-se um modelo em que o endividamento das empresas é fortemente influenciado pelo lado da oferta de recursos pelo fato de os credores e investidores (usuários do CAPM e de múltiplos de mercado) avaliarem sua exposição e nível de risco em bases relativas (empresas similares). Esse comportamento induz a estrutura de capital-alvo das empresas ao endividamento mediano do setor, restando aos gestores apenas gerenciar sua estrutura de capital em torno desse valor (folga financeira). Como objetivo, investigou-se o papel da folga financeira, avaliada como uma medida de endividamento relativo, e do endividamento setorial sobre o rebalanceamento da estrutura de capital das empresas. Para tanto, utilizou-se uma amostra inicial de empresas americanas com 32.309 observações-ano para estimar as medianas setoriais de 64 setores e uma subamostra de 5.380 observações, representando ainda 58 setores, para a construção de um painel balanceado por um período de 20 anos. Os resultados do painel dinâmico para o endividamento contábil indicam que o endividamento da empresa tende a acompanhar o endividamento setorial, porém tendem a reverter sua tendência em um período de dois anos. A velocidade de reversão está associada à folga financeira, ou seja, empresas mais distantes do endividamento mediano do seu setor convergem mais rapidamente.

Palavras-chave: estrutura de capital; folga financeira; rebalanceamento.

\begin{abstract}
We assume a model in which a firm's indebtedness is strongly influenced by a fund's supply side because creditors and investors (users of CAPM and market multiples) assess their exposure and risk level at relative bases (similar companies). This behavior induces firms' capital structure targets towards the industry debt median, so managers can just manage capital structure around this value (financial slack). We investigated the role of financial slack, assessed as a measure of relative indebtedness, and industry debt in capital structure rebalancing. We used an initial sample of 32,309 US firm-year observations to estimate the industry median of 64 industries and a subsample of 5,380 observations in 58 industries used to construct a balanced panel for a period of 20 years. The results of the dynamic panel for book leverage indicate that a company's indebtedness tends to follow industry indebtedness, but tends to reverse its trend in a period of two years. Reversion rate is associated with financial slack, i.e., companies farthest from the median debt in an industry converge faster.
\end{abstract}

Key words: capital structure; financial slack; rebalancing. 


\section{Introdução}

Ainda se sabe muito pouco sobre como as empresas escolhem a sua estrutura de capital e o que se sabe tem apenas efeitos marginais na sua explicação (Lemmon, Roberts, \& Zender, 2008; Myers, 1984). Um dos fatores identificados e pouco compreendidos é a influência do setor sobre a empresa. A relevância do endividamento setorial na escolha da estrutura de capital está evidenciada nos trabalhos de Frank e Goyal (2009) e Lemmon, Roberts e Zender (2008), entre outros. Sua relevância pode ser explicada por capturar efeitos de fatores omitidos (Hovakimian, Hovakimian, \& Tehranian, 2004) ou que os gestores consideram seu setor como benchmark para ajustar sua estrutura de capital (Hull, 1999), o que caracteriza um ajuste na estrutura de capital pelo lado da demanda por recursos.

Usuários do Capital Asset Princing Model (CAPM) e de múltiplos de mercado geralmente admitem que empresas do mesmo setor possuem nível de risco similar. Este trabalho propõe que os provedores de recursos controlam a oferta de capital para as empresas de modo a gerenciar seus próprios níveis de exposição e de risco assumidos, e o fazem restringindo o endividamento setorial mediano.

Aos gestores, pelo lado da demanda por recursos, restariam apenas ajustes menores em torno do endividamento setorial para atingir seus objetivos. Esse endividamento relativo entre as empresas de um mesmo setor é a forma como o conceito de folga financeira é operacionalizado neste estudo.

O objetivo foi investigar se o conceito de folga financeira (endividamento relativo) pode ser um dos determinantes de estrutura de capital mesmo controlando, para outros efeitos, segundo um modelo no qual o nível de endividamento setorial é limitado pelo lado da oferta enquanto que os ajustes estão relacionados com o conceito de folga financeira (endividamento relativo).

Os resultados encontrados sugerem que as empresas são fortemente influenciadas pelo endividamento do seu setor de atividade e que as mais distantes do endividamento mediano do setor tendem a convergir mais rapidamente para esse valor. Esse fenômeno ocorre em um ciclo aproximado de dois anos. Tais resultados foram obtidos com dados de um período de 20 anos de empresas americanas para o endividamento contábil através da análise de painel dinâmico (efeitos fixos). As evidências sugerem a relevância do conceito de folga financeira e suportam a visão de que o endividamento das empresas é fortemente influenciado pela oferta de fundos. O modelo estimado com dados de endividamento a valores de mercado não se mostrou apropriado para inferências.

Após uma revisão da literatura sobre estrutura de capital, apresenta-se a metodologia adotada, uma discussão sobre os resultados e, em seguida, as considerações finais.

\section{Referencial Teórico}

Lemmon et al. (2008) identificam duas características não explicadas pelos determinantes de estrutura de capital tradicionais: a primeira é a convergência de empresas altamente alavancadas para níveis moderados e a segunda é que, apesar da convergência, os níveis de alavancagem permanecem consideravelmente estáveis ao longo do tempo. A conclusão dos autores é que esses níveis são caracterizados por um componente transitório e outro permanente.

As alterações, ao longo do tempo, da estrutura de capital, transitórias ou permanentes, poderiam ser: de caráter aleatório; resultantes de ações discricionárias dos gestores na demanda por novos fundos para projetos; resultantes da oferta excessiva ou restrição de crédito; ou ainda um conjunto desses fatores.

Ao considerar a ação discricionária dos gestores, deve-se avaliar a possibilidade de geração de valor para os acionistas através da estrutura de capital, pois, se isso for possível, há razões para crer que os gestores procurem administrar a estrutura de capital de suas empresas, o que remete às discussões de 
Modigliani e Miller (1958, 1963) e Miller (1977). Em não havendo custos para ajustar a estrutura de capital, segundo a teoria do trade-off, cada empresa deveria estar sempre no ponto que maximiza o seu valor, porém a existência de custos para esses ajustes e o tempo necessário para sua realização poderiam explicar os desvios em relação ao endividamento ideal.

Na teoria do pecking order não há menção a um endividamento ótimo, mas o endividamento seria uma consequência entre as condições de assimetria de informação com o mercado e o surgimento de bons projetos. Nesse contexto, os gestores devem ficar atentos aos custos das fontes de financiamento sem se preocupar em atingir uma determinada estrutura de capital-alvo.

$\mathrm{Na}$ hipótese em que haja gerenciamento ativo da estrutura de capital, as empresas deveriam considerar os benefícios e custos associados a cada nível de endividamento disponível e escolher a melhor estrutura de capital. Sempre que a empresa for deslocada desse ponto, ela deveria rebalancear sua estrutura considerando os custos de transação envolvidos (Leary \& Roberts, 2005).

Se a oferta de fundos para as empresas for ilimitada, a questão mais relevante para o ajuste da estrutura de capital são os custos de ajustes (fricções de mercado), mas, diante de restrições atuais ou possíveis restrições financeiras futuras, a manutenção ou gerenciamento da uma folga financeira pode ser desejável.

\section{Folga financeira}

No survey realizado, por Graham e Harvey (2001), com os Chief Financial Officers (CFOs), estes responderam sobre quais fatores afetavam o modo como escolhem o montante apropriado de dívidas de suas empresas e indicaram como principal fator a flexibilidade financeira. Os respondentes deveriam considerar flexibilidade financeira como uma restrição na emissão de dívidas que produz um excedente de recursos internos, ou seja, não comprometidos com o pagamento de juros, que viabilizariam a implementação de novos projetos quando estes surgissem.

A ideia de flexibilidade financeira não é nova. Lintner (1956) considera que os acionistas não aprovam mudanças bruscas na política de dividendos e, portanto, seria adequada a existência de recursos internos para fazer frente à ciclicidade e volatilidade dos resultados, para que as alterações na política de dividendos, se e quando implementadas, fossem suaves.

Sendo o objetivo principal da empresa maximizar o seu valor no longo prazo para os acionistas e credores, a empresa possui outro mais urgente: sobreviver a choques internos ou externos no curto prazo. Para sobreviver a tais choques, as empresas podem manter uma quantidade ociosa de recursos à sua disposição, esse "colchão" é o que Bourgeois (1981, p. 30) caracteriza como folga organizacional. Ainda segundo o autor, esse excesso pode ser usado para resolver diversos problemas organizacionais ou para perseguir objetivos fora do paradigma da busca pela otimização dos recursos aplicados, por exemplo, suportando o processo de inovação.

A folga financeira é apenas uma das possibilidades de se obter folga organizacional e pode ser caracterizada principalmente por dois componentes: (a) liquidez, ou seja, a habilidade de converter ativos em recursos monetários com o menor desconto possível em relação ao seu valor intrínseco, tratado aqui como folga financeira de curto prazo; e (b) o que Myers (1984) definiu como poder de empréstimo reserva ao referir-se à capacidade de emitir dívida se necessário, o que se optou por classificar como folga financeira de longo prazo. Assim, folga financeira de curto prazo está relacionada ao caixa, aplicações financeiras e outros ativos circulantes mantidos pelas empresas. Já a folga financeira de longo prazo é gerenciada mantendo-se a alavancagem atual em um nível que a empresa considere possível aumentar ainda mais seu endividamento sem pressionar demasiadamente seu risco.

Dessa forma, a folga financeira pode ser vista como uma opção ou seguro, pois, na visão de Holmström e Tirole (2000), se uma empresa for alvo de um evento exógeno que ponha em risco a sua continuidade, terá dificuldade de levantar fundos necessários para se recuperar, pois estará em situação adversa para oferecer garantias aos credores. 
Acharya, Almeida e Campello (2007) investigaram a relação entre liquidez das empresas e endividamento. Os autores defendem que caixa não é necessariamente equivalente à dívida negativa (redução de endividamento), mas que diferentes combinações de caixa e dívida estão associadas a diferentes distribuições de investimento em estados futuros. Em um mundo segundo o modelo ArrowDebreu, a estrutura de capital das empresas seria irrelevante, pois elas não precisariam manter ativos líquidos e não haveria ganhos com gerenciamento de risco se o mercado fosse completo (Holmström \& Tirole, 2000).

O gerenciamento da folga financeira dar-se-ia através da gestão da estrutura de capital com a manutenção de capacidade de endividamento ociosa, portanto faz-se necessária uma análise longitudinal e relativa às demais empresas para verificar sua presença.

Estratégias de avaliação do comportamento dinâmico da estrutura de capital, de modo geral, especificam uma estrutura-alvo teórica a partir de um modelo baseado em determinantes clássicos de estrutura de capital. Tal procedimento produz um valor teórico como estrutura de capital-alvo para determinar o quão distante a empresa encontra-se desse valor. Fama e French (2002) adotaram essa estratégia na tentativa de identificar se há reversão da alavancagem para estruturas-alvo. Os autores utilizaram como determinantes: oportunidade de investimento, lucratividade, volatilidade, benefícios fiscais não oriundos do uso de dívida, tamanho da empresa, proporção de distribuição de dividendos para estimar a alavancagem ótima para o período seguinte e apurar a diferença entre o valor teorizado e o verificado. Korajczyk e Levy (2003) seguiram a mesma linha de ação, porém incluíram em seu modelo variáveis macroeconômicas.

Outra forma é considerar a mediana do endividamento dentro de um setor como estrutura de capital-alvo das empresas (Hovakimian, Opler, \& Titman, 2001). Essa abordagem justifica-se dado o papel relevante da medida do setor de atividade em explicar o endividamento das empresas (Frank \& Goyal, 2009; Lemmon et al., 2008).

\section{Endividamento setorial}

Este trabalho considera o endividamento-alvo das empresas não uma função de determinantes selecionados da literatura, mas a mediana do setor. Após trabalhos com resultados contraditórios sobre a existência de diferença na estrutura de capital entre setores de atividades, Bowen, Daley e Huber (1982) e Bradley, Jarrell e Kim (1984) trouxeram evidências significativas que suportam a existência de diferenças entre a estrutura de capital de setores de atividades. Bowen et al. (1982) também identificaram certa estabilidade no endividamento setorial ao longo do tempo e observaram que o endividamento das empresas tem a tendência de oscilar em torno da média em intervalos de cinco a dez anos.

Na comparação entre a relevância dos determinantes tradicionais e dos fatores específicos de cada empresa (elementos idiossincráticos) na capacidade de explicar a estrutura de capital, Lemmon et al. (2008) mostraram o baixo poder de explicação dos determinantes tradicionais, embora entre estes destaque-se a relevância relativa da mediana do endividamento setorial em relação às demais variáveis.

Frank e Goyal (2009) identificaram resultados empíricos contraditórios na literatura sobre estrutura de capital e, após testarem diversos determinantes, identificaram seis fatores como os mais relevantes, sendo a alavancagem setorial mediana o principal deles. Os demais são: tangibilidade, lucratividade, tamanho da empresa, a razão entre o valor de mercado dos ativos e o seu valor contábil e a expectativa de inflação.

Os trabalhos citados anteriormente não mencionam as possíveis razões teóricas que explicam o setor de atividade como fator determinante. Uma delas seria a relação entre os tipos de produto e serviço fornecidos pela empresa a seus clientes, conforme proposto por Titman (1984). A argumentação é que, quando o encerramento da atividade de determinadas empresas gera grandes custos aos envolvidos (fornecedores e clientes), devido à sua especificidade e às suas competências únicas, há incentivos para um menor endividamento do setor como forma de reduzir os riscos de todos os participantes. Os 
resultados obtidos por Kale e Shahrur (2007), ao investigarem a relação entre estrutura de capital das empresas e as características de seus clientes e fornecedores, suportam a proposta de Titman, pois há evidências de que as empresas reduzem seu endividamento para induzir outros membros da cadeia vertical a aceitarem estabelecer relações de longo prazo através de investimentos específicos.

A relevância do endividamento setorial na determinação da estrutura de capital pode ser uma questão de demanda ou oferta de fundos, ou seja, empresas demandam aproximadamente o mesmo volume de capital pelas características similares de seus negócios e oportunidades de investimento (ambiente de negócios) ou os ofertantes de crédito utilizam-se da mediana do setor para avaliar o risco envolvido na operação e, dessa forma, limitar maiores graus de alavancagem.

Há uma pressão para que as empresas em dificuldades financeiras reduzam seu endividamento para se ajustarem ao endividamento setorial, as evidências podem ser encontradas em Gilson (1997), que investigou os efeitos dos custos de transação dessas operações fora e dentro dos tribunais (recuperação judicial). Também como evidência do papel de benchmarking do endividamento setorial, Evans (1991 como citado em Gilson, 1997) afirma que consultores de empresas que atuam em processos de reestruturação também utilizam o endividamento setorial como referência para seus clientes.

Apesar de restrições de crédito terem sido relacionadas a restrições de investimentos, Fazzari e Petersen (1993 como citado em Almeida, Campello, \& Weisbach, 2004) encontraram evidências de que investimentos estão mais sujeitos à existência de fundos internos de financiamento. Se for considerado que há uma dispersão na lucratividade (fonte de financiamento interno) entre os setores, esse fato poderia explicar as diferentes necessidades por demanda de capital entre eles.

Baker e Wurgler (2002) propõem que a estrutura de capital atual é um processo de acumulação de oportunidades através do qual as empresas se aproveitam de imperfeições temporárias do mercado, momentos em que há uma alteração relativa entre o custo de capital próprio comparado com outras fontes de financiamento. Sendo as janelas similares para as empresas do mesmo setor, fatores idiossincráticos poderiam permitir o seu aproveitamento, inclusive para gerar folga financeira. Nesse sentido, Alti (2006) verifica que as empresas aproveitam-se de janelas de oportunidade para abertura de capital, capitalizando-se no momento em que o mercado parece-lhes favorável, mas o autor afirma que, em um prazo de até dois anos, as empresas retornam ao seu nível de endividamento anterior.

Se as janelas forem formadas a partir de fatores macroeconômicos, faria todo o sentido considerálos nos modelos de estrutura de capital. Korajczyk e Levy (2003) avaliaram a relação entre as condições macroeconômicas e as escolhas sobre estrutura de capital de empresas, separando-as em dois grupos: com e sem dificuldades de acesso a fontes de capital externo. Os autores encontraram evidências que o ambiente macroeconômico é significante para emissões de empresas, em especial para as que não têm restrições para acessar o mercado financeiro. Outra evidência foi que o nível de endividamento é diretamente relacionado ao estado da economia para as empresas com acesso ao mercado financeiro, ou seja, elas se endividam mais em momentos favoráveis. Já as empresas no grupo oposto têm uma relação de endividamento inverso, estas aproveitam o momento favorável para reduzir seu endividamento.

Há evidências que empresas aproveitam-se também das baixas taxas de juros para lançarem títulos de dívida. Barry, Mann, Mihov e Rodríguez (2008) pesquisaram se as emissões de dívida estavam relacionadas apenas ao aumento de investimentos e encontraram evidências de que as emissões superam as necessidades de capital. Esse resultado também corrobora o que os executivos relataram a Graham e Harvey (2001).

Barry et al. (2008) encontraram relação entre a série histórica de taxa de juros e o número de emissões de dívida. A abordagem originou-se no desejo de separar a teoria neoclássica de investimentos, segundo a qual uma redução no custo de capital favorece os investimentos e a possibilidade das empresas usarem janelas de oportunidade. Assim, os autores compararam o nível de investimento das empresas com as taxas de juros e verificaram que as empresas emitem mais dívida do que o necessário para suas necessidades de investimento quando as taxas estão historicamente baixas. 
A influência do endividamento setorial sobre a estrutura de capital, mesmo controlando pelas características que tornam as empresas similares (de modo que sejam classificadas em um setor), pode ser um efeito da regulação da oferta de crédito conduzida pelos provedores de fundos por perceberem riscos similares para empresas do mesmo setor. A alternativa dos administradores é manter a estrutura de capital dentro de uma faixa em que, na percepção de risco dos credores, ficaria em um nível aceitável. Essa faixa de operação seria a folga financeira (baixo ou alto endividamento) à disposição do gestor. Para verificar essa possibilidade, foi testado um modelo dinâmico considerando o endividamento setorial mediano e a folga financeira.

\section{Metodologia da Pesquisa}

A estratégia adotada é identificar, através de um painel de dados dinâmico, o comportamento (significância estatística e sinais) das variáveis defasadas de endividamento e folga financeira controlando para outros efeitos. Inicialmente, considerou-se duas defasagens para a variável endividamento, pois Leary e Roberts (2005) sugerem que os ajustes da estrutura de capital para uma faixa desejável ocorrem em um período de dois a quatro anos. Além disso, incluiu-se as variáveis de folga financeira de curto e longo prazo, que são objeto de interesse deste trabalho, e diversas variáveis de controle: cinco das seis apontadas por Frank e Goyal (2009) como relevantes (com exceção da expectativa de inflação, que caracterizar-se-ia como um efeito comum a todas as empresas em cada ano); e duas relacionadas à teoria do trade-off (a taxa marginal de impostos e a probabilidade de dificuldades financeiras), já que esta propõe a existência de um ponto ótimo para o endividamento. Os modelos representados nas equações 1 e 2 foram testados mais adiante.

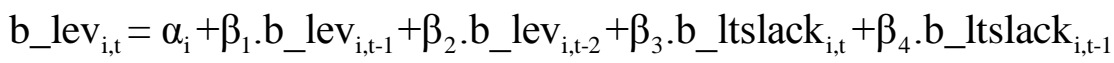

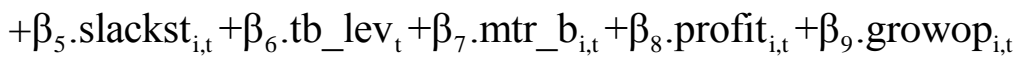

$$
\begin{aligned}
& +\beta_{10} \cdot \text { zscore }_{\mathrm{i}, \mathrm{t}}+\beta_{11} \cdot \operatorname{tang}_{\mathrm{i}, \mathrm{t}}+\beta_{12} \cdot \text {. } \mathrm{ize}_{\mathrm{i}, \mathrm{t}}+\mathrm{u}_{\mathrm{i}, \mathrm{t}}
\end{aligned}
$$

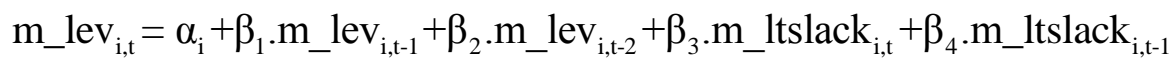

$$
\begin{aligned}
& +\beta_{5} \cdot \text { slackst }_{\mathrm{i}, \mathrm{t}}+\beta_{6} \cdot \mathrm{tm}_{-} \text {lev }_{\mathrm{t}}+\beta_{7} \cdot \mathrm{mtr}_{-} \mathrm{b}_{\mathrm{i}, \mathrm{t}}+\beta_{8} \cdot \text { profit }_{\mathrm{i}, \mathrm{t}}+\beta_{9} \cdot \text { growop }_{\mathrm{i}, \mathrm{t}} \\
& +\beta_{10} \cdot \text { zscore }_{\mathrm{i}, \mathrm{t}}+\beta_{11} \cdot \operatorname{tang}_{\mathrm{i}, \mathrm{t}}+\beta_{12} \cdot \operatorname{size}_{\mathrm{i}, \mathrm{t}}+\mathrm{u}_{\mathrm{i}, \mathrm{t}}
\end{aligned}
$$

Onde: b_lev é o endividamento contábil; $\mathbf{m} \_l e v$ é o endividamento a valor de mercado; b_ltslack é a folga financeira de longo prazo (endividamento relativo) a valores contábeis; m_ltslack é a folga financeira de longo prazo (endividamento relativo) a valores de mercado; sltackst é a folga financeira de curto prazo (liquidez corrente); tb_lev é o endividamento-alvo a valores contábeis; tm_lev é o endividamento-alvo a valores de mercado; mtr_b é a alíquota marginal de impostos; profit é a lucratividade; growop é a oportunidade de crescimento; zscore é a dificuldade financeira; tang é a tangibilidade; e size é tamanho.

\section{Operacionalização das variáveis}

Esta seção descreve a operacionalização das variáveis utilizadas no modelo. As medidas de endividamento contábil (b_lev) e de endividamento a valor de mercado (m_lev) foram avaliadas como:

$$
\text { b_lev }=\frac{\text { Debt }}{\text { Book Assets }}
$$




$$
\mathrm{m} \_ \text {lev }=\frac{\text { Debt }}{\text { Market Value }+ \text { Debt }}
$$

Onde: Debt é a dívida financeira total (curto prazo + longo prazo); Book Assets é o valor contábil dos ativos; e Market Value é o valor de mercado do patrimônio líquido.

O endividamento-alvo a valores contábeis (tb_lev) e o endividamento-alvo a valores de mercado (tm_lev) foram estimados como a mediana de cada setor em cada ano. Presume-se que esses valores representem a estrutura de capital ótima.

A folga financeira de longo prazo a valores contábeis (b_ltslack) ou a valores de mercado (m_ltslack) é estimada considerando a distribuição dos endividamentos de todas as empresas do setor a que pertencem, de acordo com a classificação de três dígitos da Standard Industrial Classification (SIC). Dessa forma, trata-se de uma medida de endividamento relativo avaliado conforme as equações 5 e 6 .

$$
\begin{aligned}
& \text { b_ltslack } \mathrm{i}_{\mathrm{i}, \mathrm{t}}=\frac{\text { tb_lev }_{\mathrm{i}, \mathrm{t}}-\mathrm{b} \_l e \mathrm{v}_{\mathrm{i}, \mathrm{t}}}{\mathrm{s}_{\mathrm{SIC}, \mathrm{t}}}
\end{aligned}
$$

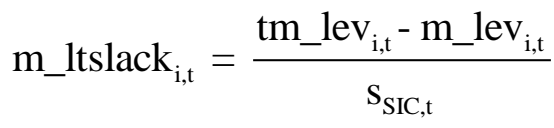

Onde: SSIC,t é o desvio padrão dos endividamentos das empresas de um mesmo setor no ano t.

Assim, quanto maior o valor da variável folga financeira de longo prazo, menor é o endividamento relativo da empresa dentro do seu setor.

As demais variáveis foram assim definidas:

slackst - Folga financeira de curto prazo. Avaliada pelo índice de liquidez seca das empresas, definido pela razão entre a soma das disponibilidades e total de recebíveis com prazo de até um ano pelo passivo circulante.

mtr_b - Alíquota marginal de imposto. Essa proxy foi desenvolvida por Graham (1996a, 1996b), calculada e disponibilizada para mais de 10.000 empresas no período de 1980 até os anos recentes. Existem duas implementações dessa variável: antes e depois das decisões de financiamento. Utiliza-se a mtr_b que considera o efeito marginal anterior às decisões de financiamento para evitar problemas de endogenia.

profit - Lucratividade da empresa. Avaliada pela razão entre o lucro antes dos impostos, juros, depreciação e amortização (EBITDA) e o valor dos ativos, isso para evitar problemas de endogenia com o endividamento.

growop - Oportunidades de crescimento. Definida como a razão entre o valor de mercado e o valor contábil dos ativos, uma aproximação do Q de Tobin.

zscore - Dificuldades financeiras. A proxy para dificuldades financeiras é o Z de Altman calculado e disponibilizado diretamente pela base de dados Compustat ${ }^{\circledR}$.

tang - Tangibilidade. Pretende avaliar a proporção dos ativos da empresa que podem ser oferecidos como colateral e é estimada pela razão entre o valor líquido do imobilizado e total dos ativos.

size - Tamanho. A variável tamanho é calculada através do logaritmo natural dos ativos, onde seu valor foi corrigido pelo índice de preços ao consumidor americano (em inglês, CPI). 


\section{Amostra e subamostra}

Para o desenvolvimento deste trabalho foi composta uma amostra de empresas americanas extraída da base de dados Compustat ${ }^{\circledR}$ considerando dados de frequência anual durante o intervalo de 1990 a 2009, ou seja, um período de 20 anos (selecionado pela disponibilidade de dados no início da pesquisa). Adotou-se os seguintes critérios para exclusão de empresas da amostra:

1. Utilizando a classificação histórica do Standard Industrial Classification (SIC) como critério, as empresas classificadas como financeiras em cada ano foram retiradas da amostra, ou seja, empresas classificadas entre os códigos 6000 e 6999.

2. Empresa que não tiveram um valor de receita de vendas ou de ativos superiores a 10 milhões de dólares (ano-base de 2005) corrigidos pelo índice de inflação americana Consumer Price Index (CPI) e aquelas que não dispunham dessas informações. A escolha do ponto de corte foi arbitrária, porém a expectativa é de que ações de empresas maiores sejam mais líquidas. O ano de 2005 foi escolhido para evitar possíveis efeitos específicos da crise de 2008 na seleção da amostra.

3. Também foram retiradas as observações que continham valores de patrimônio líquido negativo.

4. Aquelas que são ou foram originalmente listadas em outros países, ou seja, foram eliminados todos American Depositary Receipts (ADRs) e similares.

Nesse ponto, a amostra ficou com 32.309 observações distribuídas entre 64 setores conforme apresentado na Tabela 1.

Tabela 1

Número de Observações por Ano

\begin{tabular}{|c|c|c|c|c|c|c|c|c|c|c|}
\hline Ano & 1990 & 1991 & 1992 & 1993 & 1994 & 1995 & 1996 & 1997 & 1998 & 1999 \\
\hline Observações & 1.208 & 1.282 & 1.359 & 1.469 & 1.606 & 1.327 & 1.749 & 1.818 & 1.919 & 1.783 \\
\hline Ano & 2000 & 2001 & 2002 & 2003 & 2004 & 2005 & 2006 & 2007 & 2008 & 2009 \\
\hline Observações & 1.871 & 1.877 & 1.788 & 1.765 & 1.763 & 1.781 & 1.626 & 1.571 & 1.446 & 1.301 \\
\hline
\end{tabular}

Nota. Total de observações $=32.309$.

1. Foram eliminadas as empresas que não possuíam ao menos cinco observações consecutivas (dentro de 20 possíveis) após os filtros anteriores.

2. Após os passos anteriores, as empresas foram agrupadas em seus respectivos setores considerando a classificação SIC com três algarismos e foram eliminados todos os setores (com as respectivas empresas) que não possuíssem ao menos 10 empresas-observações.

A partir dessa amostra, estimou-se a mediana de endividamento setorial a valores contábeis (tb_lev) e a valores de mercado (tm_lev), os quais foram utilizados também para estimativa das variáveis de folga financeira.

As correlações entre as variáveis envolvidas nesta pesquisa são apresentadas na Tabela 2, em que é possível identificar a alta correlação esperada entre as proxies de endividamento. Percebe-se as correlações negativas entre as medidas de endividamento e as variáveis de folga financeira (b_lev e b_ltslack; m_lev e m_ltslack), o que também era esperado dado o processo de construção da variável folga financeira. Nota-se, também, as correlações positivas entre endividamento e a mediana do setor (b_lev e tb_lev; m_lev e tm_lev); esse é um indicativo de que as empresas podem considerar o endividamento setorial como benchmark. 
Tabela 2

\section{Correlação entre as Variáveis}

\begin{tabular}{|c|c|c|c|c|c|c|c|c|c|c|c|c|c|}
\hline Obs. 27.316 & b_lev & m_lev & b_ltslack & m_ltslack & slackst & tb_lev & tm_lev & mtr_b & profit & growop & zscore & tang & Size \\
\hline b_lev & 1 & & & & & & & & & & & & \\
\hline m_lev & 0,831 & 1 & & & & & & & & & & & \\
\hline b_ltslack & $-0,731$ & $-0,546$ & 1 & & & & & & & & & & \\
\hline m_ltslack & $-0,651$ & $-0,793$ & 0,783 & 1 & & & & & & & & & \\
\hline Slackst & $-0,328$ & $-0,347$ & 0,161 & 0,228 & 1 & & & & & & & & \\
\hline tb_lev & 0,468 & 0,475 & 0,232 & 0,070 & $-0,274$ & 1 & & & & & & & \\
\hline tm_lev & 0,459 & 0,509 & 0,191 & 0,061 & $-0,281$ & 0,940 & 1 & & & & & & \\
\hline mtr_b & 0,038 & $-0,011$ & 0,074 & 0,103 & $-0,102$ & 0,152 & 0,143 & 1 & & & & & \\
\hline Profit & $-0,048$ & $-0,131$ & 0,126 & 0,200 & $-0,078$ & 0,098 & 0,073 & 0,519 & 1 & & & & \\
\hline growop & $-0,246$ & $-0,392$ & 0,086 & 0,279 & 0,227 & $-0,250$ & $-0,280$ & $-0,021$ & 0,150 & 1 & & & \\
\hline Zscore & $-0,359$ & $-0,348$ & 0,238 & 0,270 & 0,506 & $-0,210$ & $-0,224$ & 0,071 & 0,212 & 0,604 & 1 & & \\
\hline Tang & 0,381 & 0,352 & 0,042 & $-0,017$ & $-0,297$ & 0,608 & 0,601 & 0,115 & 0,150 & $-0,188$ & $-0,201$ & 1 & \\
\hline Size & 0,179 & 0,130 & $-0,058$ & $-0,029$ & $-0,277$ & 0,198 & 0,221 & 0,347 & 0,281 & $-0,031$ & $-0,094$ & 0,161 & 1 \\
\hline
\end{tabular}

Nota. Onde: b_lev é o endividamento contábil; $\mathbf{m} \_l e v$ é o endividamento a valor de mercado; $\mathbf{b} \_l t s l a c k$ é a folga financeira a valores contábeis; $\mathbf{m} \_l t s l a c k$ é a folga financeira a valores de mercado; tb_lev é o endividamento alvo a valores contábeis avaliado pela mediana do setor; tm_lev é o endividamento alvo a valores de mercado avaliado pela mediana do setor; $\mathbf{m t r} \_\mathbf{b}$ é a alíquota marginal de impostos; profit é a lucratividade; growop é a oportunidade de crescimento; zscore é a dificuldade financeira; tang é a tangibilidade; e size é tamanho. 
Pode ser observado também que empresas maiores (size) e com mais colateral (tang) a oferecer são mais endividadas; empresas com menor probabilidade de sofrerem de dificuldades financeiras (zscore), com maiores oportunidades de crescimento (growop) e lucrativas (profit) são as menos endividadas. Essas relações estão em linha com a teoria.

Espera-se que empresas com maior endividamento possuam uma alíquota marginal de impostos (mtr_b) menor, porém as correlações são próximas de zero e sem sinal definido.

Chama a atenção a alta correlação $(0,94)$ entre as medianas de endividamento setorial avaliadas a valores contábeis e de mercado (tb_lev e tm_lev). Lembrando-se que valores contábeis refletem decisões implementadas no passado, enquanto valores de mercado são formulados considerando expectativas de desempenho futuro, a princípio não seria esperada uma correlação tão alta. Uma possível explicação é que talvez o endividamento mediano também seja proxy para as condições de mercado (ciclos econômicos).

A partir dessa amostra, retirou-se uma subamostra composta por 269 empresas, cobrindo 58 setores, que dispunham de todas as informações durante todo o período em análise ( 20 anos), com o objetivo de obter um painel fortemente balanceado para estimação dos painéis de dados. A subamostra contém 5.380 observações e as estatísticas descritivas tanto da amostra como da subamostra podem ser conferidas na Tabela 3.

Tabela 3

Estatísticas Descritivas da Amostra e Subamostra

\begin{tabular}{lccccccccccc}
\hline Amostra & & \multicolumn{1}{c}{ Subamostra } \\
\hline Variável & Obs & Média & D.P. & Min & Max & Variável & Obs & Média & D.P. & Min & Max \\
\hline b_lev & 32.309 & 0,203 & 0,180 & 0,000 & 0,935 & b_lev & 5.380 & 0,216 & 0,150 & 0,000 & 0,722 \\
m_lev & 32.309 & 0,211 & 0,222 & 0,000 & 1,000 & m_lev & 5.380 & 0,213 & 0,191 & 0,000 & 0,930 \\
b_ltslack & 32.309 & $-0,187$ & 0,978 & $-5,934$ & 4,722 & b_ltslack & 5.380 & $-0,150$ & 0,885 & $-3,541$ & 2,824 \\
m_ltslack & 32.309 & $-0,486$ & 1,155 & $-7,783$ & 3,693 & m_ltslack & 5.380 & $-0,389$ & 0,995 & $-5,573$ & 2,071 \\
slackst & 32.309 & 1,936 & 2,354 & 0,000 & 50,810 & slackst & 5.380 & 1,494 & 1,586 & 0,009 & 22,182 \\
tb_lev & 32.309 & 0,175 & 0,122 & 0,000 & 0,571 & tb_lev & 5.380 & 0,196 & 0,118 & 0,000 & 0,521 \\
tm_lev & 32.309 & 0,138 & 0,120 & 0,000 & 0,665 & tm_lev & 5.380 & 0,159 & 0,123 & 0,000 & 0,573 \\
mtr_b & 27.316 & 0,285 & 0,112 & 0,000 & 0,395 & mtr_b & 5.380 & 0,320 & 0,081 & 0,000 & 0,394 \\
profit & 32.309 & 0,105 & 0,138 & $-2,014$ & 0,872 & profit & 5.380 & 0,146 & 0,081 & $-0,603$ & 0,548 \\
growop & 32.309 & 1,947 & 1,862 & 0,220 & 105,120 & growop & 5.380 & 1,850 & 1,295 & 0,420 & 25,470 \\
zscore & 32.309 & 5,021 & 9,596 & $-84,169$ & 726,649 & zscore & 5.380 & 4,589 & 4,525 & $-3,588$ & 86,571 \\
Tang & 32.309 & 0,309 & 0,247 & 0,000 & 0,986 & tang & 5.380 & 0,360 & 0,239 & 0,011 & 0,956 \\
Size & 32.309 & 5,742 & 1,863 & 2,303 & 12,895 & size & 5.380 & 6,930 & 1,842 & 2,435 & 12,840 \\
\hline
\end{tabular}

Nota. Onde: b_lev é o endividamento contábil; $\mathbf{m} \_l e v$ é o endividamento a valor de mercado; b_ltslack é a folga financeira a valores contábeis; m_ltslack é a folga financeira a valores de mercado; tb_lev é o endividamento alvo a valores contábeis avaliado pela mediana do setor; tm_lev é o endividamento-alvo a valores de mercado avaliado pela mediana do setor; mtr_b é a alíquota marginal de impostos; profit é a lucratividade; growop é a oportunidade de crescimento; zscore é a dificuldade financeira; tang é a tangibilidade; e size é tamanho. 


\section{Resultados}

Para a estimação dos modelos, optou-se por trabalhar com a subamostra que possui dados para todas as variáveis durante todo o período coberto, de modo a formar um painel balanceado.

Antes da estimação dos modelos, investigou-se a existência de raízes unitárias através do teste de Levin-Lin-Chun, o qual rejeita a hipótese de raízes unitárias para as variáveis dependentes b_lev e m_lev. Os resultados são apresentados na Tabela 4. Apesar de não relatado, também descartou-se a presença de raízes unitárias nas variáveis de endividamento alvo (tb_lev e tm_lev).

Tabela 4

\section{Teste de Raiz Unitária para as Variáveis Dependentes}

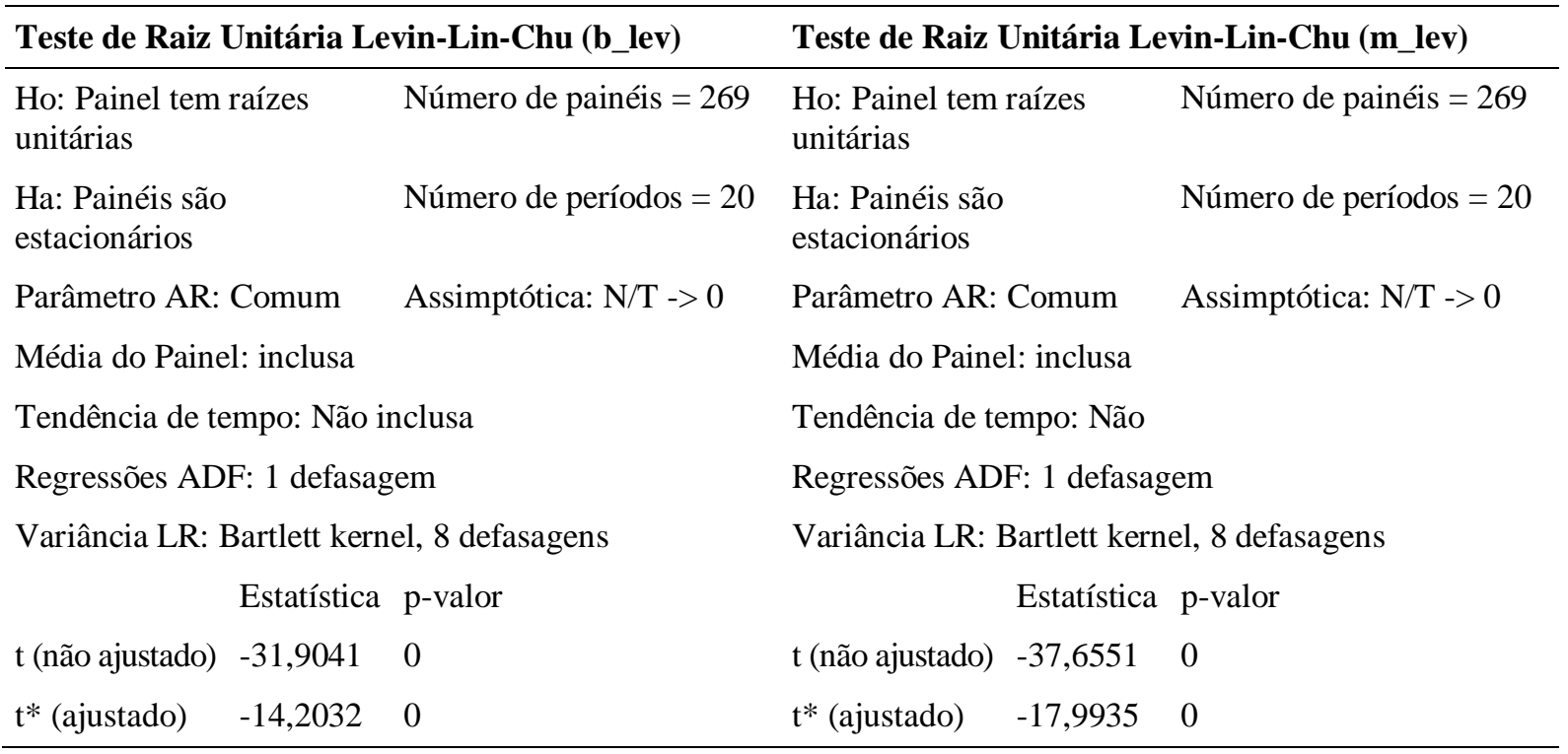

Nota. Fonte: Elaborada pelos autores.

Os modelos de painel dinâmico representados pelas equações 1 e 2 foram estimados através do comando xtabond2, desenvolvido por Roodman (2009), que implementa as propostas de ArellanoBover e Blundell-Bond (GMM), estimado com dois passos, com a opção de tratamento de erros padrão do tipo robusto (prevenindo problemas com heterocedasticidade).

Os resultados (efeitos fixos) para o modelo representado pela equação 1 para a variável endividamento (b_lev) estão apresentados na Tabela 5. Percebe-se que o teste de Arellano-Bond de primeira ordem não rejeita a presença de autocorrelação, o que é esperado pela estimação em diferenças, enquanto o de segunda ordem rejeita sua presença. O teste de Sargan de sobreidentificação do modelo não pode ser rejeitado a $10 \%$ de significância, porém o teste de Hansen rejeita problemas de sobreidentificação. Diante desses fatos, aceitou-se o modelo como válido. 
Tabela 5

Painel Dinâmico Estimado em Dois Passos por Gmm em Diferenças com Variáveis Defasadas (B_Lev)

\begin{tabular}{|c|c|c|c|c|c|c|}
\hline \multicolumn{2}{|c|}{ Variável de grupo: } & \multicolumn{2}{|l|}{ gvkey } & \multicolumn{2}{|c|}{ Número de observações = } & 4573 \\
\hline \multicolumn{2}{|c|}{ Variável de tempo: } & \multicolumn{2}{|l|}{ ano } & \multicolumn{2}{|c|}{ Número de grupos = } & 269 \\
\hline \multicolumn{2}{|c|}{ Número de instrumentos $=$} & \multicolumn{2}{|l|}{25} & \multirow{2}{*}{ Observ. por grupo: } & $\min .=$ & 17 \\
\hline \multicolumn{2}{|c|}{ Wald chi2 $(12)=$} & \multicolumn{2}{|l|}{8430,56} & & média $=$ & 17 \\
\hline \multicolumn{2}{|c|}{ Prob $>$ chi $2=$} & \multicolumn{2}{|l|}{0,0000} & & $\max .=$ & 17 \\
\hline b_lev & Coef. & $\begin{array}{c}\text { Erro padrão } \\
\text { corrigido }\end{array}$ & Estatística z & $\mathrm{P}>\mathrm{z}$ & [Intervalo d & le confiança 95\%] \\
\hline L1.b_lev & 0,162 & 0,055 & 2,940 & $0,003 * * *$ & 0,054 & 0,269 \\
\hline L2.b_lev & $-0,210$ & 0,076 & $-2,780$ & $0,006 * * *$ & $-0,359$ & $-0,062$ \\
\hline bltslack & $-0,134$ & 0,006 & $-22,940$ & $0,000 * * *$ & $-0,146$ & $-0,123$ \\
\hline L1.bltslack & $-0,002$ & 0,011 & $-0,230$ & 0,818 & $-0,023$ & 0,018 \\
\hline slackst & 0,000 & 0,001 & 0,200 & 0,844 & $-0,001$ & 0,002 \\
\hline tb_lev & 0,848 & 0,055 & 15,550 & $0,000 * * *$ & 0,741 & 0,955 \\
\hline mtr_b & 0,024 & 0,015 & 1,640 & $0,100 *$ & $-0,005$ & 0,053 \\
\hline profit & $-0,478$ & 0,215 & $-2,230$ & $0,026^{* *}$ & $-0,899$ & $-0,058$ \\
\hline growop & 0,005 & 0,002 & 2,330 & $0,020 * *$ & 0,001 & 0,009 \\
\hline zscore & 0,000 & 0,000 & $-1,270$ & 0,204 & $-0,001$ & 0,000 \\
\hline $\operatorname{tang}$ & 0,024 & 0,023 & 1,040 & 0,297 & $-0,021$ & 0,070 \\
\hline size & 0,053 & 0,022 & 2,470 & $0,013 * *$ & 0,011 & 0,096 \\
\hline
\end{tabular}

Instrumentos para a equação de primeiras diferenças

$\begin{array}{ll}\text { Padrão: } & \text { D.(bltslack slackst tb_lev mtr_b growop zscore tang size) } \\ \text { Tipo GMM: } & \text { L2.b_lev }\end{array}$

Teste Arellano-Bond para AR(1) nas primeiras diferenças: $\quad \mathrm{z}=-3,46 \quad \operatorname{Pr}>\mathrm{z}=0,001$

Teste Arellano-Bond para AR(2) nas primeiras diferenças: $\quad \mathrm{z}=1,08 \quad \operatorname{Pr}>\mathrm{z}=0,279$

Teste de Sargan: $\quad$ chi2 $(13)=20,74$

Prob $>$ Chi $2=0,078$

(Não é robusto, mas não é enfraquecido pelo uso de muitos instrumentos)

Teste de Hansen: $\quad$ chi2 $(13)=16,20$

Prob $>$ Chi2 $=0,239$

(Robusto, mas enfraquecido pelo uso de muitos instrumentos)

Nota. Os coeficientes foram estimados pela técnica de Arellano-Bover/Blundell-Bond para painéis dinâmicos considerando a variável b_lev como dependente. Fonte: Elaborada pelos autores.

Os asteriscos referem-se ao nível de significância do p-valor: * (significante a 10\%), ** (significante a 5\%) e *** (significante a $1 \%$ ). Os prefixos L1e L2 significam respectivamente a primeira e segunda defasagens da variável a que estão associados.

O endividamento anterior (primeira defasagem) afeta o endividamento atual com sinal positivo, enquanto a segunda defasagem apresenta sinal negativo. Isso é um indício de consistência, pois o modelo não se mostra explosivo (uma impossibilidade teórica e prática para endividamento). A variável de folga financeira mostrou-se significativa e com sinal negativo, porém sua versão defasada não apresentou relevância no modelo. 
Uma interpretação possível dos resultados é que o endividamento contábil possui certa inércia para se ajustar quando se considera os sinais da variável endividamento de até dois anos anteriores sobre o endividamento atual. Isso pode ser resultado de fatores externos alheios à vontade do gestor, tais como custos de transação que impedem ou desestimulam ajustes mais rápidos, ou de que os gestores permitam deliberadamente que a estrutura de capital oscile dentro de uma faixa ótima de endividamento, de modo que as decisões de rebalanceamento da estrutura de capital sejam postergadas.

Observando-se o endividamento-alvo (mediana do setor) e a folga financeira (endividamento relativo), parece existirem duas forças atuando na correção da estrutura de capital ao longo do tempo: uma em nível e outra transitória.

Ao considerar o nível de endividamento setorial como um fator resultante da demanda de capital pelas empresas (presume-se oferta ilimitada de capital), é como se existisse um efeito manada. Assim, sempre que houvesse uma alteração de comportamento na estrutura de capital do setor, seja por janelas de oportunidade, condições macroeconômicas, oportunidades de investimento ou qualquer outra conjuntura positiva ou negativa, as empresas procurariam mimetizar tal comportamento.

Outra possibilidade é analisar os resultados pelo lado da oferta (agora, presume-se demanda ilimitada de capital), supondo que condições externas afetem os provedores de recursos de modo que estes aumentem ou reduzam a oferta de fundos (ajuste de exposição) para cada setor conforme suas características (riscos percebidos), forçando as empresas a ajustarem as suas estruturas de capital. Esse cenário parece ser mais realístico e coerente com as evidências sobre restrições de capitais e efeitos de assimetria de informação (Faulkender \& Petersen, 2006; Goyal, Nova, \& Zanetti, 2011).

Se o poder realmente estiver na mão dos provedores de recursos, a folga financeira é o recurso disponível aos gestores para gerenciar o seu ciclo de negócios, por exemplo, para a realização de investimentos significativos ou recuperar-se de decisões anteriores equivocadas. Essa característica transitória evidenciaria por que folgas financeiras passadas não têm poder explicativo sobre a estrutura de capital atual.

Os demais resultados das variáveis de controle podem ser comparados com os resultados de Frank e Goyal (2009). A Tabela 6 tem essa função, nela nota-se uma grande semelhança entre os resultados.

Tabela 6

Comparativo entre os Resultados do Modelo (B_Lev) e Frank e Goyal (2009)

\begin{tabular}{lll}
\hline Fator & Frank e Goyal (2009) & Modelo (B_Lev) \\
\hline Alavancagem mediana do setor & Positiva & Positiva \\
Tangibilidade & Positiva & Não significativa \\
Lucratividade & Negativa & Negativa \\
Tamanho & Positiva & Positiva \\
Razão entre os valores de mercado e contábil dos ativos & Negativa & Positiva \\
Expectativa de inflação & Positiva & Não investigado \\
Folga financeira de longo prazo & Não Investigado & Negativa \\
\hline
\end{tabular}

Nota. Fonte: Elaborada pelos autores.

As diferenças estão na variável tangibilidade (tang), que não apresentou significância estatística, e na razão entre os valores de mercado e o contábil dos ativos, tratado aqui como oportunidade de crescimento (growop), que apresentou uma relação positiva, contrariando o esperado.

Os resultados da estimação do modelo baseado na equação 2 estão apresentados na Tabela 7 , porém, conforme os resultados dos testes de autocorrelação e sobreidentificação, não se pode considerar 
o modelo digno de inferências e, portanto, seus resultados não serão comentados. Também se investigou empiricamente o uso de modelos com três defasagens, tanto para o endividamento contábil como para o endividamento a valor de mercado, no entanto os modelos não se mostraram significativos.

Tabela 7

Painel Dinâmico Estimado em Dois Passos por GMM em Diferenças com Variáveis Defasadas (m_lev)

\begin{tabular}{|c|c|c|c|c|c|c|}
\hline \multicolumn{2}{|c|}{ Variável de grupo: } & \multicolumn{2}{|l|}{ gvkey } & \multicolumn{2}{|c|}{ Número de observações $=$} & 4573 \\
\hline \multicolumn{2}{|c|}{ Variável de tempo: } & \multicolumn{2}{|l|}{ ano } & \multicolumn{2}{|l|}{ Número de grupos $=$} & 269 \\
\hline \multicolumn{2}{|c|}{ Número de instrumentos = } & \multicolumn{2}{|l|}{25} & \multirow[t]{2}{*}{ Observ. por grupo: } & $\min .=$ & 17 \\
\hline \multicolumn{2}{|c|}{ Wald chi2 $2(12)=$} & \multicolumn{2}{|l|}{1583,35} & & média $=$ & 17 \\
\hline \multicolumn{2}{|l|}{ Prob $>$ chi $2=$} & \multicolumn{2}{|l|}{0,0000} & & $\max .=$ & 17 \\
\hline m_lev & Coef. & $\begin{array}{c}\text { Erro Padrão } \\
\text { Corrigido }\end{array}$ & Estatística z & $\mathrm{P}>\mathrm{z}$ & \multicolumn{2}{|c|}{ [Intervalo de confiança 95\%] } \\
\hline L1.m_lev & 0,167 & 0,070 & 2,400 & $0,016^{* *}$ & 0,031 & 0,304 \\
\hline L2.m_lev & $-0,026$ & 0,043 & $-0,610$ & $0,540^{*}$ & $-0,110$ & 0,058 \\
\hline mltslack & $-0,165$ & 0,007 & $-22,910$ & $0,000 * * *$ & $-0,179$ & $-0,151$ \\
\hline L1.mltslack & 0,053 & 0,019 & 2,780 & $0,005 * * *$ & 0,016 & 0,090 \\
\hline slackst & 0,001 & 0,003 & 0,320 & 0,752 & $-0,005$ & 0,007 \\
\hline tm_lev & 1,151 & 0,056 & 20,710 & $0,000 * * *$ & 1,042 & 1,260 \\
\hline mtr_b & $-0,081$ & 0,031 & $-2,620$ & $0,009 * * *$ & $-0,142$ & $-0,020$ \\
\hline profit & 1,195 & 0,305 & 3,920 & $0,000 * * *$ & 0,598 & 1,792 \\
\hline growop & $-0,008$ & 0,004 & $-2,130$ & $0,033^{* *}$ & $-0,015$ & $-0,001$ \\
\hline zscore & $-0,002$ & 0,002 & $-1,350$ & 0,177 & $-0,006$ & 0,001 \\
\hline $\operatorname{tang}$ & $-0,112$ & 0,067 & $-1,670$ & $0,095^{*}$ & $-0,243$ & 0,019 \\
\hline size & $-0,097$ & 0,030 & $-3,250$ & $0,001 * * *$ & $-0,156$ & $-0,039$ \\
\hline
\end{tabular}

Instrumentos para a equação de primeiras diferenças

Padrão:

D.(mltslack slackst tm_lev mtr_b growop zscore tang size)

Tipo GMM: L2.m_lev

Teste Arellano-Bond para AR(1) nas primeiras diferenças: $\quad z=-4,04$

$\operatorname{Pr}>\mathrm{z}=0,000$

Teste Arellano-Bond para $\operatorname{AR}(2)$ nas primeiras diferenças: $\quad \mathrm{Z}=-1,97$

$\operatorname{Pr}>\mathrm{z}=0,049$

Teste de Sargan:

$$
\operatorname{chi} 2(13)=53,29
$$

Prob $>$ Chi $2=0,000$

(Não é robusto, mas não é enfraquecido pelo uso de muitos instrumentos)

Teste de Hansen:

$$
\operatorname{chi} 2(13)=39,23
$$

Prob $>$ Chi $2=0,000$

(Robusto, mas enfraquecido pelo uso de muitos instrumentos)

Nota. Os coeficientes foram estimados pela técnica de Arellano-Bover/Blundell-Bond para painéis dinâmicos considerando a variável M_Lev como dependente. Fonte: Elaborada pelos autores.

Os asteriscos referem-se ao nível de significância do p-valor: * (significante a 10\%), ** (significante a 5\%) e *** (significante a 1\%). Os valores apresentados abaixo dos coeficientes são os respectivos p-valores. Os prefixos L1 e L2 significam respectivamente a primeira e segunda defasagens da variável a que estão associados. 


\section{Comentários Finais}

Há evidências de que o endividamento contábil passado (até duas defasagens) afeta o nível de endividamento atual, contudo verifica-se certa inércia no ajuste da estrutura de capital, a qual seria compatível com a presença de custos de transação para ajustes contínuos ou com a existência de uma faixa ótima de estrutura de capital, dentro da qual os gestores permitem oscilações. Esses fatos conduziriam a uma postergação das ações de rebalanceamento da estrutura de capital.

Supondo que o endividamento-alvo ideal das empresas não é conhecido pelos gestores ex-ante, aceitou-se que a mediana do setor deveria ser a melhor proxy possível para esse conceito. Este trabalho se propôs a verificar o papel da folga financeira de longo prazo (avaliada como endividamento relativo) no rebalanceamento da estrutura de capital e encontrou indícios do seu papel em explicar a estrutura de capital corrente, porém, ao investigar-se a persistência dos seus efeitos, esta mostrou-se baixa, pois não foi possível encontrar significância estatística na variável defasada.

A interpretação econômica da folga financeira de longo prazo deve ser feita em conjunto com o endividamento setorial. Os resultados são compatíveis com um cenário no qual os provedores de recursos controlam a oferta de capital de modo a gerenciar suas exposições e riscos considerando características dos setores aos quais as empresas pertencem. Assim, a estrutura de capital das empresas estaria condicionada a de seus pares por representarem riscos semelhantes aos olhos dos fornecedores de recursos (visão compatível com o Capital Asset Pricing Model).

Nesse cenário de controle da oferta de recursos, a folga financeira seria gerenciada pelos gestores conforme o ciclo de seus negócios, de modo a permitir a realização de investimentos relevantes (estratégicos), entre outras possibilidades. A sua baixa persistência pode estar relacionada ao horizonte de planejamento orçamentário típico de um ano da maioria das empresas.

Não foi possível inferir os mesmos resultados a partir do endividamento a valores de mercado, pois o modelo não passou nos testes de sobreidentificação e autocorrelação.

Este trabalho também confirmou alguns resultados conhecidos na literatura sobre os determinantes clássicos da estrutura de capital e o papel extremamente relevante do endividamento setorial sobre a estrutura de capital das empresas, como em Frank e Goyal (2009).

Os resultados foram obtidos a partir de uma subamostra que contém dados de empresas ao longo de 20 anos para a construção de um painel balanceado, porém isso pode ter introduzido um viés de sobrevivência e, portanto, as suposições aqui levantadas devem ser tratadas com o devido cuidado, ao mesmo tempo em que abrem oportunidades metodológicas para novos trabalhos.

Outra possibilidade de estudos futuros é avaliar a influência do prazo de vencimento das dívidas de longo prazo. Diferenças no prazo de vencimento poderiam afetar a escolha das estruturas-alvo. Próximo ao vencimento de dívidas e em condições adversas para sua rolagem, determinadas empresas podem reter lucros acima do desejado ou reduzir forçosa e temporariamente o endividamento, aguardando condições de mercado mais propícias para captações de recursos de terceiros. Assim, uma possível relação a ser explorada no futuro em termos de folga financeira é o prazo médio de vencimento das dívidas. Possivelmente, empresas com um perfil de dívida mais alongado possuem a seu favor possibilidades de renegociação e quitação antecipada, de modo a oferecer outro tipo de flexibilidade financeira.

Parece existir na literatura evidências suficientes, às quais este trabalho soma-se, da necessidade de modelar dinamicamente os processos de determinação da estrutura de capital de empresas. 


\section{Referências}

Acharya, V. V., Almeida, H., \& Campello, M. (2007). Is cash negative debt? A hedging perspective on corporate financial policies. Journal of Financial Intermediation, 16(4), 515-554. doi: 10.1016/j.jfi.2007.04.001

Almeida, H., Campello, M., \& Weisbach, M. S. (2004). The cash flow sensitivity of cash. The Journal of Finance, 59(4), 1777-1804. doi: 10.1111/j.1540-6261.2004.00679.x

Alti, A. (2006). How persistent is the impact of market timing on capital structure? The Journal of Finance, 61(4), 1681-1710. doi: 10.1111/j.1540-6261.2006.00886.x

Baker, M., \& Wurgler, J. (2002). Market timing and capital structure. The Journal of Finance, 57(1), 132. doi: $10.1111 / 1540-6261.00414$

Barry, C. B., Mann, S. C., Mihov, V. T., \& Rodríguez, M. (2008). Corporate debt issuance and the historical level of interest rates. Financial Management, 37(3), 413-430. doi: 10.1111/j.1755053X.2008.00019.x

Bourgeois, L. J., III (1981). On the measurement of organizational slack. The Academy of Management Review, 6(1), 29-39. doi: 10.5465/AMR.1981.4287985

Bowen, R. M., Daley, L. A., \& Huber, C. C., Jr. (1982). Evidence on the existence and determinants of inter-industry differences in leverage. Financial Management, 11(4), 10-20. doi: $10.2307 / 3665227$

Bradley, M., Jarrell, G. A., \& Kim, E. H. (1984). On the existence of an optimal capital structure: theory and evidence. The Journal of Finance, 39(3), 857-878. doi: 10.1111/j.1540-6261.1984.tb03680.x

Fama, E. F., \& French, K. R. (2002). Testing trade-off and pecking order predictions about dividends and debt. The Review of Financial Studies, 15(1), 1-33. doi: 10.1093/rfs/15.1.1

Faulkender, M., \& Petersen, M. A. (2006). Does the source of capital affect capital structure? The Review of Financial Studies, 19(1), 45-79. doi: 10.1093/rfs/hhj003

Frank, M. Z., \& Goyal, V. K. (2009). Capital structure decisions: which factors are reliably important? Financial Management, 38(1), 1-37. doi: 10.1111/j.1755-053X.2009.01026.x

Gilson, S. C. (1997). Transactions costs and capital structure choice: evidence from financially distressed firms. The Journal of Finance, 52(1), 161-196. doi: 10.1111/j.15406261.1997.tb03812.x

Goyal, V. K., Nova, A., \& Zanetti, L. (2011). Capital market access and financing of private firms. International Review of Finance, 11(2), 155-179. doi: 10.1111/j.1468-2443.2011.01131.x

Graham, J. R. (1996a). Debt and the marginal tax rate. Journal of Financial Economics, 41(1), 41-73. doi: 10.1016/0304-405X(95)00857-B

Graham, J. R. (1996b). Proxies for the corporate marginal tax rate. Journal of Financial Economics, 42(2), 187-221. doi: 10.1016/0304-405X(96)00879-3

Graham, J. R., \& Harvey, C. R. (2001). The theory and practice of corporate finance: evidence from the field. Journal of Financial Economics, 60(2/3), 187-243. doi: 10.1016/S0304-405X(01)00044-7

Holmström, B., \& Tirole, J. (2000). Liquidity and risk management. Journal of Money, Credit and Banking, 32(3), 295-319. 
Hovakimian, A., Hovakimian, G., \& Tehranian, H. (2004). Determinants of target capital structure: the case of dual debt and equity issues. Journal of Financial Economics, 71(3), 517-540. doi: $10.1016 / \mathrm{S} 0304-405 \mathrm{X}(03) 00181-8$

Hovakimian, A., Opler, T., \& Titman, S. (2001). The debt-equity choice. Journal of Financial \& Quantitative Analysis, 36(1), 1-24. doi: 10.2307/2676195

Hull, R. M. (1999). Leverage ratios, industry norms, and stock price reaction: an empirical investigation of stock-for-debt transactions. Financial Management, 28(2), 32-45.

Kale, J. R., \& Shahrur, H. (2007). Corporate capital structure and the characteristics of suppliers and customers. Journal of Financial Economics, 83(2), 321-365. doi: 10.1016/j.jfineco.2005.12.007

Korajczyk, R. A., \& Levy, A. (2003). Capital structure choice: macroeconomic conditions and financial constraints. Journal of Financial Economics, 68(1), 75-109. doi: 10.1016/s0304-405x(02)00249-0

Leary, M. T., \& Roberts, M. R. (2005). Do firms rebalance their capital structures? The Journal of Finance, 60(6), 2575-2619. doi: 10.1111/j.1540-6261.2005.00811.x

Lemmon, M. L., Roberts, M. R., \& Zender, J. F. (2008). Back to the beginning: persistence and the cross-section of corporate capital structure. Journal of Finance, 63(4), 1575-1608. doi: 10.1111/j.1540-6261.2008.01369.x

Lintner, J. (1956). Distribution of incomes of corporations among dividens, retained earnings, and taxes. The American Economic Review, 46(2), 97-113.

Miller, M. H. (1977). Debt and taxes. The Journal of Finance, 32(2), 261-275. doi: 10.1111/j.15406261.1977.tb03267.x

Modigliani, F., \& Miller, M. H. (1958). The cost of capital, corporation finance and the theory of investiment. The American Economic Review, 48(3), 37.

Modigliani, F., \& Miller, M. H. (1963). Corporate income taxes and the cost of capital: a correction. The American Economic Review, 53(3), 433-443.

Myers, S. C. (1984). The capital structure puzzle. The Journal of Finance, 39(3), 574-592. doi: 10.1111/j.1540-6261.1984.tb03646.x

Roodman, D. (2009). How to do xtabond2: an introduction to difference and system GMM in Stata. Stata Journal, 9(1), 86-136.

Titman, S. (1984). The effect of capital structure on a firm's liquidation decision. Journal of Financial Economics, 13(1), 137-151. doi: 10.1016/0304-405X(84)90035-7

\title{
Dados dos Autores
}

\author{
Anderson Luis Saber Campos \\ Rua Alfeu Tavares, 149, 09641-000, São Bernardo do Campo, SP, Brasil. E-mail: alscampos@uol.com.br \\ Wilson Toshiro Nakamura \\ Rua da Consolação, 930, 01302-090, São Paulo, SP, Brasil. E-mail: wtnakamura@uol.com.br
}

